Journal of Systems Science and Information

Apr., 2021, Vol. 9, No. 2, pp. 131-153

DOI: $10.21078 /$ JSSI-2021-131-23

\title{
Analysis of the Impacts of Work, Non-Work and Stress Issues on the Work Family Conflict in Ivorian Industrial Sector
}

\author{
Aristide Gbame CHOKI \\ School of Economics and Management, Beihang University, Beijing 100191, China; \\ LIMAK AFRIKA, Human Resources Department, Km 23 Abidjan, Cote d'Ivoire \\ E-mail: gbame@gmx.com \\ Qiuhong ZHAO \\ School of Economics and Management, Beihang University, Beijing 100191, China \\ E-mail: qhzhao@buaa.edu.cn
}

\begin{abstract}
This paper analyzes the perceptions that workers in the Ivorian industrial sector have as the interface between their professional and personal life, and the factors that facilitate or make it difficult. Data collected from 4 Ivorian industrial companies which represent a sample of 187 respondents according to the selection criteria. These collected data make it possible to identify the factors which act on the labor conflict towards the family as well as the factors which act on the family conflict towards the work within the industrial sector in Cte d'Ivoire. The results of the correlation coefficients show that the relationships between the proposed variables are significant and in the direction suggested for the most part, thus providing support for nine of the ten hypotheses affecting these relationships. According to some results obtained, it was discovered that certain factors could be at the same time, factors of conflict and satisfaction, such as the commitment to work or the nature of the work. These variables can simultaneously increase stress, and increase the self-esteem of the worker. The results of the analysis of the proposed model recommend the possibility that the data fit the model well, explaining the impacts of work, non-work and stressors on work-family conflict. This indicates that the proposed model is adapted to the Ivorian context.
\end{abstract}

Keywords work-family conflict; job performance; non-work; stress; coefficient of correlation

\section{Introduction}

Work-family conflict is an unavoidable social reality. And, in this reality, the majority of women in the labor market also have an important part of the responsibility; especially parental.

Historically, the two most important pillars of an adult's life have been and remain work and family. These two pillars (work and family) are variables that allow adults to assert themselves. This affirmation of the adult through these two pillars, participates in a unique way to help us understand the behavior of the human being. Our review of the literature has shown us that a lot of theoretical and empirical research has been carried out in the field of these two important pillars of the human being. The observation that emerges is that these researches on these two pillars was carried out independently. However, for some researchers, these two variables are

Received January 15, 2021, accepted March 28, 2021 
closely related. Thus, the work of these researchers led them to discover that the relationship between work and family appears in the form of conflict. It has also been observed that many changes in work and/or family generate increasing tensions between these two spheres (work and family) of life. This makes it increasingly difficult for some employees to maintain a balance between these two spheres ${ }^{[1]}$.

For the first time, researchers define work-family conflict by examining the difference between people, between their professional roles and their other daily behaviors. They pointed out that work-family conflict arises when the demands of work and the demands of the family are diametrically opposed to some extent and, conclude that conflict exists when the demands of a role in an area affect the ability to respond the requirements of another role in the other domain $^{[2]}$.

Today, the growing population growth increases the workforce, including the entry of more and more women into the labor market. The desire to improve the living conditions of the family, to give better education to the children, and now the new global health crisis due to COVID-19, influence families and jobs. In addition, the growing number of migrants looking for jobs or holding more and more jobs in host cities, has forced researchers to rethink research on work-family conflicts and identify their impact on this rapidly changing world.

It is obvious that in view of the current situation, it is more than necessary to conduct further researches on work-family conflicts. This need will force us to understand the causes and consequences of this concept which persists in time and culture. This will help both employers and employees to avoid the onset of the crisis or, above all, to anticipate and/or manage the negative effects of work-family or familywork conflict that may arise. Understanding the problem of work-family conflict is the first step that will help families reassess the consequences of work-family conflict in order to take measures to deal with the negative consequences of these conflicts; which will be very beneficial for families and workers. Finally, it is also necessary, and even very important for organizations, in their interest to identify the issues linked to workfamily conflicts and the factors with a high impact in order to allow managers to have more tools and solutions. to avoid the organizational consequences of these work-family conflicts.

Based on the results of studies conducted by Greenhaus and his colleagues ${ }^{[2]}$, the researchers reoriented their work by moving from contagion and compensatory reactance modules to causal modules in order to explain the antecedents and consequences of work-family conflict. Carlson $\& \mathrm{Kacmar}^{[3]}$, like many other researchers have proposed such models but unfortunately, by not focusing their tests on certain types of consequences, hence the omission of many other types of possible consequences. The models suggested to date have all shown their limits. Thus, only the modules presenting the direct (proximal) consequences of work-family conflict were mainly studied to the detriment of the module which presents the mediated (distal) consequences of work-family conflict. Our ability after this study to better grasp and understand exactly how these results manifested themselves is limited by only taking into account the mainly direct impact of the factors identified on work-family conflicts. The researchers then felt ill-equipped to understand and better explain the work, non-work and stress factors in work-family conflict and how they occur; because several important ways to explore were excluded from primary research. Finally, to lay the foundations for the model proposed in this research, theories will 
be presented. The model that the researcher proposes in this study finds its anchoring in Spillover theory, focusing on the impact of work-related conflicts, non-workrelated conflicts and stress-related conflicts through series of proximal and distal relationships.

\section{Literature Review}

The majority of researchers are inspired by the definition of Greenhaus and Beutell ${ }^{[2]}$. The latter had defined the work-family theme as a form of conflict between the different roles held by the same person. Thus, most of the literature review focuses on workers' experiences of work, family and family roles in particular, and examines the characteristics of employees participating in different roles.

\subsection{Overview of Work-Family Conflict}

The concept of work-family conflict is part of the new forms of human resources management practices, particularly in the context of quality of work life programs, organization of working time and services offered to employees in light of changes in the world of work and society. It is therefore necessary to clarify the relevance of certain concepts in order to carry out the research. In the literature, other terms are used such as work-family balance, work-family articulation, the job-family link and, more recently, the intrusion of work life on personal life. Whether we are talking about the work-family relationship or the workfamily relationship, the reality studied remains the same. The use of the terms conciliation, balance or articulation is a matter of preference for each author. In our paper, we retain the term work-family conflict for the following sections.

According to Nielson, et al. ${ }^{[4]}$, work-family conflict can take three forms: Time conflict, role tension and behavioural conflict; specified by Tremblay ${ }^{[5]}$ as follows:

\section{$\checkmark$ Time conflict results from the overload of multiple roles and the difficulty in coordinating the competing demands of each}

- Tension conflict arises from tension experienced in one role, whose participation in another role interferes with it.

- Behavioural conflict occurs when the specific behaviour in one role is incompatible with the expected behaviour in another role; especially when necessary adjustments have not been made.

In addition, St-Onge, et al. identified three different ways of interpreting work-life conflict: One-way, two-way and multidimensional.

Several types of conflict are potentially present in employees' lives, such as "work-spouse" conflict, "work-family" conflict, "work-home" conflict, and "work-study" conflict. According to Greenhaus and Beutell ${ }^{[2]}$, when work and family demands are to some extent incompatible, this can constitute a form of conflict, as involvement in one role makes it difficult to be involved in the other. In other words, the conflict between these two spheres of an individual's life results from a lack of time to accomplish the different tasks required in one and the other. Role encroachment can also be a cause of work-family conlicts: This is the case, for example, when the individual brings his or her work home, or when he or she arrives home tired because the 
work is too demanding and requires long hours. Sometimes, work-family conflict can cause the individual to return home with behaviours that affect family life.

\subsubsection{Variables Influencing Work-Family Conflict}

Why do some families have no difficulty balancing work and family life while others are highly affected and experiencing conflict? Job and employee characteristics can be variables that influence the level of complexity in balancing work and family. Table 1 presents the different characteristics.

Table 1 Variables influencing work-family conflict

\begin{tabular}{cc}
\hline Characteristics of the job & Characteristics of the employee \\
\hline Hours worked & Personality \\
Time to get to work & Gender \\
Overtime & Age \\
Irregular shifts & Number of children \\
Rigid work schedule & Age of children \\
Ambiguity of work & Spousal involvement \\
Role conflicts & Spousals job \\
Overwork & Earnings \\
Lack of superior understanding & Importance of family \\
\hline
\end{tabular}

Other variables that influence work-life conflict, such as an employee's marital status, commitment to work, commitment to family, career stage, presence in the family of an elderly relative or a person with a disability who requires regular care, and family type. Job characteristics also play a role in the extent of conflict. Sector of activity, socio-professional category. The nature of the roles must also be taken into account. Of course, in the work environment, other variables are crucial, such as the presence of work-life balance practices, the attitude of superiors and the attitude of co-workers.

\subsubsection{Domains of Work-Family Conflict}

The conflict between work and family or between family and work is experienced in two areas (at home and at work) as its expression indicates. Individuals feel and act in a hostile manner when their person or property is hurt or threatened or when they are prevented from achieving their goals.

1. Family-to-work conflict experienced at work

Perceptions of family-to-work conflict indicate that interfering with family issues at work prevents employees from achieving their career goals.

2. Family-to-work conflict experienced at home 
In the family domain, when employees are faced with conflict between work and family, they are prevented from fulfilling their family obligations and engaging in important family activities (spending more time with children and loved ones).

Thus, a more difficult work-life balance could have an impact on work. More important could be parental dissatisfaction with their work, decreased motivation or productivity, or higher rates of return, absenteeism or turnover. However, the impact of work-family conflict on personal and family life would be greater than the impact on the workplace.

\subsection{Theoretical Approaches of the Proposed Models}

A number of researchers have proposed theories that describe the relationship between work and family life. Among the recent literature, the main theories described are: Conflict, identity, compensation, boundaries and spillover. Among them, the spillover theory has been the most frequently discussed in relation to the other theories identified. Developed by $\mathrm{Xu}^{[7]}$ as the study of the shared impacts between family and work life, this theory is based on the principle that the system (family and work) could have a "spillover impact" on each other ${ }^{[8,9]}$. Researchers indicate that experiences in one sphere (work or family) may have positive or negative impacts on the other. A positive spillover occurs when the level of success and satisfaction in one sphere positively influences the other sphere. Conversely, negative spillover occurs when the level of depression and difficulties in one (family of employees) are transferred to another sphere (work). Negative spillover results in the fact that an individual concerned (by his or her family life or by his or her work) may be less effective in carrying out the activities of the other sphere (the domestic activities of the family sphere). In summary, each sphere may include experiences (emotions, behaviours, values and abilities) that can be felt similarly in the sphere. In general, spillover effects undermine the actions of social and political institutions in understanding the relationships between family and work roles ${ }^{[10]}$.

\subsubsection{Spillover Theory: Validity and Reliability}

The purpose of this survey is to investigate the different facets of the work-family conflict and to demonstrate the applicability of the spillover theory to the context of Ivorian workers. Thus, the study is based on the following objectives: 1) to highlight the mutual effects between work and family life, including both positive and negative aspects; 2) to demonstrate how work and family roles can have a negative influence on individuals; 3 ) to establish the fact that they can have an impact on workers' ability to fulfil their parental role.

A total of 150 participants employed in the industries sectors participated in a random survey conducted from May to July 2018. Approximately $92 \%$ of participants were married or cohabiting, $78 \%$ reported having one or more children, and $8 \%$ were single parents (see descriptive statistics of participant demographics in Table 2. Respondents completed the family to work conflict indicator form ${ }^{[11]}$, examining 12 dimensions of work-family conflict and aspects of spillover theory across a total of 150 items. 
Table 2 Socio-demographic information of participants $(N=150)$

\begin{tabular}{lllc}
\hline Characteristics & $\%$ & Characteristics & $\%$ \\
\hline Sex & & Employer sector & 32 \\
\hline Male Female & 59 & Public sector Private sector & 68 \\
\hline Age & 41 & & 52 \\
\hline $21 \sim 30$ years & & Years in service & 39 \\
$31 \sim 45$ years & 18 & $1 \sim 10$ years & 12 \\
$46 \sim 65$ years & 47 & $11 \sim 20$ years & 78 \\
Academic level & 35 & $20 \sim 35$ years and over & 14 \\
Secondary level & & Type of position & 8 \\
University level & 28 & Operational level & Senior management level \\
Post graduate level & 61 & Top management level & \\
\hline
\end{tabular}

\subsubsection{Demographic Survey Analysis Results}

In addition to the extent of work-family conflict, demographic questions on age, gender, education, marital status, number of children and nature of work were asked. In addition, the survey also included questions on: Workload, motivation to work, and intention to quit.

We used SPSS 19.0 (Statistics for Social Sciences) to treat collected data. The analysis includes not only descriptive and inferential statistics but also the correlational statistics. In the framework of our goal to determine whether or not the spillover theory could be applied in Ivorian context, an exploratory factor analysis is carried out based on 5 IMFJR (Indicator for the Measurement of the Family-Job Reconciliation) components. The analysis provides eigenvalues of 80.24 representing $54.70 \%$ of the total variance, thereby giving support to the variance factor (reported in Table 3).

Components are analyzed as of a factor if their factor loading is larger than 300. Some components are authorized to be charged in more than one factor, resulting in differences in the size and complexity of the combined factors.

Table 3 Factorial identification

\begin{tabular}{llll}
\hline Work-family conflict issues & $\begin{array}{l}\text { Number of } \\
\text { components }\end{array}$ & Value & $\begin{array}{l}\text { Total variance } \\
(\%)\end{array}$ \\
\hline $\begin{array}{l}\text { Factor 1 Work-family constraint } \\
\text { impact on personal development }\end{array}$ & 23 & 16.08 & 12.42 \\
Factor 2 Work-family impact on organization & 18 & 13.42 & 10.25 \\
Factor 3 Work impact on parenting & 7 & 11.37 & 6.04 \\
Factor 4 Work-to-family positive spillover & 21 & 13.22 & 11.82 \\
Factor 5 Work-to-family negative spillover & 11 & 26.15 & 14.17 \\
\hline
\end{tabular}

Factor 1: Work-family constraints impact on personal development. The first factor explains how various family problems (family situation, family duties, worries, lack of support from family members), as well as the constraints imposed by work, can affect the management of 
family relationships and have an impact on the worker's personal growth and development. This is a heterogeneous group with a total of 23 variables which are distributed as follows: 8 variables related to work and family constraints on personal development, 7 variables related to negative family-work interactions, 7 variables expressing positive familywork interactions, and one variable related to work-related emotional experiences. As a result, participants felt that they did not have time for themselves because of work and/or family obligations. Sometimes they feel that they do not belong to themselves but to their work and/or family.

Factor 2: Work-family impact on organization. The second factor describes how family responsibilities and constraints can have a negative impact on both an individual's emotional experience and his or her ability to work well at work, perform his or her duties, and find creative solutions to workplace problems. The factor encompasses 18 variables, including 11 work-related emotional experiences and 7 negative work-family interaction variables.

Factor 3: Work impact on parenting. The third factor indicates the inability of workers (with dependent children) to perform their parenting roles and the related impacts on parent-child relationships. It contains seven variables belonging to the influence of employment on parenting. It should be noted that the responses to these variables represent $78 \%$ of the participants who reported having children.

Factor 4: Work-to-family positive spillover. The forth factor is a mixture of variables suggesting that well-being and positive interrelation among family members strongly provide the ability of participant to assume effectively their professional responsibilities. Positive experiences at family environment and at job place strengthen each other, provide personal resource and innovation in new competencies for effective problem solving in the workplace. The factor groups 21 variables: 6 variables for positive work-family correlations, 6 variables for positive family-work correlations, 8 variables for well-being at work and one size variable entitled strategies for solving the conflict between workplace and family life.

Factor 5: Work-family negative spillover. This factor is a heterogeneous one combining 11 variables. It demonstrates that participants believe that work responsibilities and the climate in the workplace have a negative impact on their engagement in family tasks. Thus, $52 \%$ of participants questioned say that the work often hampers and embarrasses them in accomplishing family responsibilities. The related variables are: 5 elements for negative impact of organizational climate on family life, three demographic indicators, concerning the number of current job, duration of the working day, frequency of obstruction caused by work against family, one variable applied to job or family - One always goes well at the expense of the other and two variables related the recent family emotional experiences: Satisfaction and Enthusiasm.

The conflict analysis from the psychological point of view, pointed out that conflict occurrences depend on the emergence of specific beliefs, perceptions, comprehension, attitudes and motivations, which have to all change for conflict resolution occurs. When analyzing the adapted theory framework between family and professional life for Ivorian context, we necessarily encounter divers psychosocial aspects.

By restructuring sociodemographic indicators and variables based on the fundamental factors, the 5 ensuing factors show how the specific characteristics of the work environment may have in overall a negative impact on family life of participants, justifying the presence of nega- 
tive spillover effect of the conflict in Ivorian context. First of all, it is clear that work issues and family stress can have an impact on individual personal development and potentials (Factor 1). Also, negative emotions felt by participants in their family life surely might negatively consequence on their capacity to deal with problems and to figure out difficulties at work (Factor 2). In addition, parenthood appears to be negatively affected by tedious tasks at job, excessive work and inconvenient obligations, among others (Factor 3). However, the well-being experienced at job and at home is capable of potentiating and activating workers, thus induce new skills that foster an effective resolution of problems at work (Factor 4). Finally factor 5, the one produced the most important result demonstrate that work activities hamper the participants in accomplishing family responsibilities.

In total, the survey was able to clearly and show the different facets of the work-family conflict and to validate the spillover theory of the work-family conflict in an Ivorian sample. However, we note that most of the participants are graduated from university with salaries generally higher than the national average but who face excessive work demands. The characteristics of the sample provide explanation of the global findings that spotlight the impact of work on the well-being of individuals and their families.

To a certain extent, our goal was to present the theoretical framework related to workfamily conflict and the underlying models. In addition, a pilot study to validate the concept of spillover theory in the Ivorian context was conducted. For us to summarize by saying that, a number of studies have suggested various models of work-family conflict by numerous scholars such as Carlson \& Kacmar ${ }^{[3]}$. They all scrutinized the spillover of work-family conflict to different domains. But, until this date solely Frone and peers ${ }^{[12]}$ study has investigated correlations (consequences) of work-family conflict in terms work-related, non-work-related and stress-related egresses. In their study, also the proximal and distal predictors of work-family conflict where examined. Exclusively only Carlson and Kacmar ${ }^{[3]}$ and Netemeyer, et al. ${ }^{[13]}$ have demonstrated models that presented proximal and distal consequences of work-family conflict.

Howsoever, none of their models has been focused wholly on investigated of the work-related, nonwork related and stress-related consequences on work-family conflict to date. Thereby, that would have allowed to identify immediate proximal reactions, which would in turn discover distal issues by means of mediated correlations. As a result, our ability to grasp the workfamily conflict concepts has persisted to be hit-and-miss and sketchy, in this way continue to alter our aptness to spur out convincing efficient scheme to minimize work-family conflict and its consequences.

\section{The Proposed Model Study}

Looking at the results of the scholars, the present research which model is suggested, will put an emphasis and investigate on points underneath. Firstly, in three distinctly specified categories, which are work-related, non-work-related and stress-related outcomes, scrutinize the consequences of work-family conflict. Secondly, from the point of view of proximal and distal outcomes, investigate those consequences. Then, discuss the mediated correlations that crop up between work-family conflict, the proximal outcomes and the distal outcomes. As well, the present study stretches out research that has been carried out previously by assessing the 
model in a sample of Cote d'Ivoire industries companies' workers. To date, no study of this nature has been conducted in Cote d'Ivoire industries companies. Based on the sources work of other investigators in the field of work-family conflict, stress, and burnout, the projected model (Figure 1) investigate the consequences of work related, non-work and stress factor on workfamily conflict and how each consequence may shepherd to one or more other consequences through sundry direct and mediated correlations. To provide a more detailed explanation of this model, each of the suggested correlations will be adumbrated and discussed.

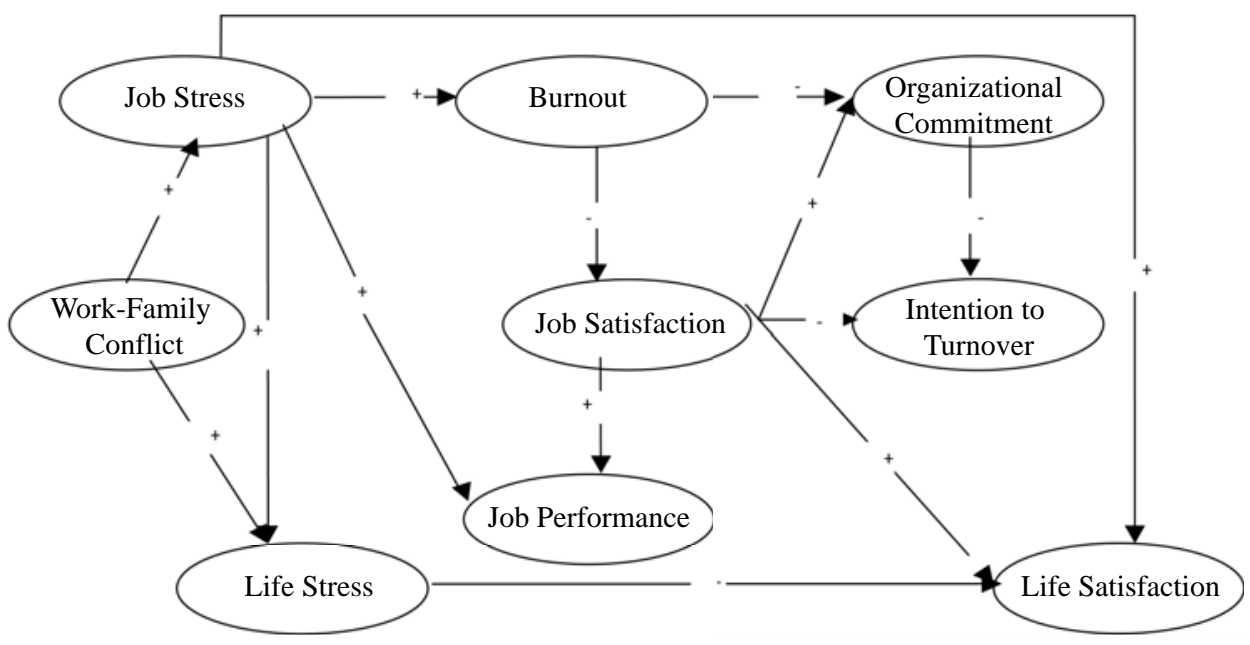

Figure 1 Proposed model of work-family conflict ${ }^{1}$

\subsection{Correlation Between Work-Family Conflict and Study Model Variables}

\subsubsection{Work-Family Conflict and Job stress}

It should be noted that work-family conflict has a direct positive relationship to job stress according to the model suggested in this study. The existence of a direct relationship between work-family conflict and workrelated stress was perceived by Netemeyer and his peers ${ }^{[13]}$. They also pointed out the hypothesis that workfamily conflict is directly related to job-stress in their study by focusing on the organizational outcomes of the work and family roles variables.

The current study suggests that the work-family conflict prognosticates the stress at work in line with previous results.

Hypothesis 1 Work-family conflict will be positively related to job-stress.

\subsubsection{Work-Family Conflict and Life Stress}

According to the model suggested in this study, work-family conflict has a direct positive relationship to family / life. Life stress term said to be referred to the "psychological response state of disturbed affect in relation to stresses in one's life" pointed out by Parasuraman, Purohit, Godshalk, \& Beutel ${ }^{[14]}$. Conceptual reviews of work-family conflict have put out life

\footnotetext{
${ }^{1}$ Figure sorted out by the author according to several researchers such as Netemeyer, et al.[13], Parasurama, et al. ${ }^{[14]}$.
} 
stress, even if the findings of empirical studies scrutinizing the relationship between work-family conflict and life stress have been conflicting.

Substantial constructive correlations of .51 and .39 has been pointed out, specifically for men and women respectively. The proposed model handles life stress as a variable that encloses general pressures of life, and the scales used are geared to estimating these general pressures. Thus, in the glowing of all these discoveries. A direct positive relationship between work-family conflict and life stress is carried out by the proposed model.

Hypothesis 2 Work-family conflict will be positively related to life stress.

\subsubsection{Mediators of Job-Stress}

Four variables that are, burnout, organizational commitment, job satisfaction and job performance, suggested by the proposed model are directly linked to job stress. More notably, the model claims to be that job stress will be positively having a link with burnout, and negatively have a link with organizational commitment, job satisfaction and job performance. These direct relationships imply that the link between work family conflict and each of these four variables is conciliated by job-stress. In the field of work-family conflict research, this tip-off is radical. It is also noted a direct relationship between work family conflict and job stress as previously discussed. These direct relationships display insinuates that there is a mediated relationship. And, yet to date, none of previous researchers has attempted to check such mediations. The present study kicks off an investigation of potential meditative role performed by job stress in the relationship between work-family conflict job burnout, organizational commitment, job satisfaction and job performance.

\subsubsection{Job Stress and Job Burnout}

According to Maslach, Schaufeli \& Leiter ${ }^{[15]}$, Burnout said to be the extension of psychological feedback to pertinacity interpersonal and emotional stressors faced on the job. That is witnessed by feelings of emotional weariness, depersonalization and scarcity of fulfillment. Antecedents of burnout have been investigated by researchers such as Hock ${ }^{[16]}$, and they mentioned that both work-family conflict and job stress directly linked to burnout. The investigation of a direct and indirect relationships between workbased role stress and its consequences, concluded that employees who faced work-family conflict would also exhibit high levels of job burnout.

More emotional exhaustion and depersonalization was reported when workers were confronted higher levels of job stress, than when they were confronted low levels of job stress. According to $\operatorname{Hock}^{[16]}$, workers who were confronted high levels of stress were more plausible to undergo burnout, reporting that job-related stress was correlated with both psychological and physical burnout, correlations of .54 and .42 yielded, respectively.

The literature review in job stress and job burnout conducted by the author has shown that direct relationships exist between work-family conflict and job stress, work-family conflict and job burnout and job stress and job burnout

Hypothesis 3a Job stress will be positively related to burnout.

Hypothesis 3b Job stress will mediate the relationship between work-family conflict and burnout. 


\subsubsection{Job Stress and Organizational Commitment}

Researchers faced difficulties to give a definition to organization commitment. Nevertheless, according to Mowday, et al. ${ }^{[17]}$, organizational commitment is the relative strength of an individuals involvement in, and identification with an organization. Organizational commitment therefore reflects to the coercion to keep a worker of an organization and bring to bear high sums of effort on behalf of that organization, regardless of ones reasons for manifesting this attitude. So, the proposed model enunciate that it exists a direct correlation between job stress and organizational engagement.

An investigation of organizational commitment pointed out that both work-family conflict and job stress led to organizational commitment. Nonetheless, the link between work family conflict and organizational commitment, according the research studies results, do not always generate outcomes to justify the existence of this relationship.

The impacts of job stress on managers and blue-collar workers have been tested among a sample of 283 blue-collar workers and 227 managers by Jamal ${ }^{[18]}$ in his study. Job stress was meaningfully linked to organizational commitment as resulted from this Jamal's study.

Hypothesis 4a Job stress will be negatively related to organizational commitment.

Hypothesis 4b Job stress will mediate the relationship between work-family conflict and organizational commitment.

\subsubsection{Job Stress and Job Satisfaction}

Job satisfaction seems to be the most popular from all variables investigated in the field of workfamily conflict and job stress literature. Researchers such as Kossek \& Ozeki ${ }^{[19]}$, revealed a direct relationship between work-family conflict and job satisfaction and, job stress and job satisfaction. Researcher Netemeyer, et al. ${ }^{[13]}$, have also suggested the possibility that workfamily conflict and job satisfaction relationship was mediated by job-stress.

Job satisfaction said to be the extent to which a worker experiments as a state of positive affectation from estimation by his or her job ${ }^{[20]}$. In a sample of working women in Singapore, a cross-cultural study investigating the antecedents and outcomes of work-family conflict, a correlation of -.31 between workfamily conflict and job satisfaction was pointed out. Netemeyer, et al. ${ }^{[21]}$, also discovered the existence of a negative link between work-family and job satisfaction who reported a correlation of -.36 . Boles, et al. ${ }^{[20]}$ pointed out, in another study, that work-family conflict was not only significantly and negatively related to job satisfaction in general, but also to all but one of the facets of job satisfaction such as satisfaction with supervision and promotion. A meta-analysis by Kossek and Ozeki ${ }^{[19]}$ also revealed that work-family conflict was negatively linked to job satisfaction, generating a mean weighted correlation of -.36. Nonetheless, the relationship between work-family conflict and job satisfaction was not a strong or as clear-cut as assumed, as revealed by many others studies conducted individually by researchers. Investigating the job related outcomes of work-family conflict in samples of American, Puerto Rican, and Romanian employees in their study, Netemeyer, et al. ${ }^{[13]}$ sorted out mixed results for the relationship between work-family conflict and job satisfaction.

There is an assumption that there would be a direct negative correlation between job stress 
and job satisfaction in a study investigating the consequences of work-family conflict, and deduct that workers who undergone high levels of job stress would be less satisfied with their jobs than those workers undergoing low levels of job stress.

The observation of the role of job stress as mediator could help to depict the discordance results pointed out when investigating the direct correlations between work-family conflict and its consequences.

Whereof, the present study by scrutinizing this mediated correlation through previous research.

Hypothesis 5a Job stress will be negatively related to job satisfaction.

Hypothesis 5b Job stress will mediate the relationship between work-family conflict and Job satisfaction.

\subsubsection{Job Stress and Job Performance}

Many studies revealed that a lowered job performance has also been observed to be a consequence of work-family conflict and job stress. The behaviors manifested by a worker and which are relevant to their job description and the demands of the workplace, and are also facing overall organizational success can be defined as job performance. According to Frone, et al. $^{[12]}$; Netemeyer, et al. ${ }^{[21]}$; and Jamal ${ }^{[19]}$, job performance is frequently determined in terms of quality of work, quantity of work and / or the amount of effort exerted (e.g., focused towards). The model suggested asserts that job stress mediates the relationship between work-family conflict and job performance.

The results of few studies investigating the relationship between work-family conflict and job performance, came out to have been discordant. Frone, et al. ${ }^{[12]}$ revealed that work family conflict was negatively linked to job performance as evaluated on a self-report performance scale, and pointing out a correlation of -.26 . Some researches revealed a weak but meaningful negative correlation between job- parent conflict and quality of work produced, but no important correlation between job-spouse and jobhomemaker conflict and quality of work. According to Netemeyer, et al. ${ }^{[21]}$, no correlation between workfamily conflict and self-report sales performance was not proved.

The relationship between job stress and job performance and work-family conflict and job stress looked alike to be robust and consistent, thereby holding up the assumption that job stress mediates the correlations between work family conflict and job performance.

Hypothesis 6a Job stress will be negatively related to job performance.

Hypothesis 6 b Job stress will mediate the relationship between work-family conflict and job performance.

\subsubsection{Life Stress and Life Satisfaction}

The suggested model claims to be that the correlations existed between work-family conflict and life satisfaction is mediated by life stress. A discussion of the direct correlations between work-family conflict and life stress have already been done. So, the relationship between workfamily conflict and, life satisfaction, life stress, and life satisfaction will be scrutinized.

Existing empirical research results investigating the relationship between work-family con- 
flict and life satisfaction have been diversified. In three distinct samples, Netemeyer, et al. ${ }^{[21]}$, in their study revealed that work-family conflict was negatively linked to life satisfaction, with correlations ranging from -.33 to -.53 . Kossek and Ozeki ${ }^{[19]}$, conducted a meta-analysis, and mentioned an average weighted mean correlation of -.31 . Also, studies, revealed a meaningful negative average correlation of -.28 between work-family conflict and life satisfaction. Nonetheless, different studies have pointed out results that counterbalanced these findings. Job-spouse conflict, and job-parent conflict were negatively linked to life satisfaction with correlations of -.33 and -.28 , respectively. These inconsistent results appear to recommend that there may be a third variable that is directly linked to both work-family conflict and life satisfaction that mediates the correlations between these two variables. The presence of a mediator would give assistant to describe the discordance outcomes in evaluating the direct correlation between these two variables. The proposed model evokes that this variable is life stress. This mediated correlation has not yet been scouted about in the literature and so, this study launches the investigation of the indirect correlations between work-family conflict and life satisfaction.

Investigation justifying the correlations between life stress and life satisfaction will now be discussed with the aim of providing more proof for the proposed mediation. From these investigation, Hart ${ }^{[22]}$ revealed that non-job stressors were established to have strong negative correlations to non-work satisfaction and general life satisfaction in police officers. Investigation inter role conflict, and on and off-job outcomes revealed that psychological strain was meaningfully linked to off-job satisfaction showing a correlation of -.45. As for $\mathrm{Lu}^{[23]}$, investigating the well-being through a sample of Chinese participants, revealed that life stress was negatively correlated to life satisfaction. When for Chang and Sanna ${ }^{[24]}$, in their studies, they also pointed out that life stress was negatively related to life satisfaction and a meaningful correlation of -.27 was shown. The proposed model confirms that stress will mediate the correlation between work-family conflict and life satisfaction.

Hypothesis 7a Life stress will be negatively related to life satisfaction.

Hypothesis 7b Life stress will mediate the relationship between work-family conflict and life satisfaction.

\subsubsection{Mediators of Intentions to Turnover}

Intention to turnover said to be the furthermost from consequences of work-family conflict as claimed to be in the proposed model. The model advocates that the relationship between job stress and intention to turnover is mediated by burnout, organizational commitment and job satisfaction, because it the final result of other outcomes. It has been discovered that each of every three variables have constant and solid links to intention to turnover. Nevertheless, before going through each of these three variables of antecedents of intention to turnover, the paper will go through over the relationship between work-family conflict and intention to leave, and the relationship between job stress and intention to turnover.

The correlation between work-family conflict and intention to turnover have put forward mixed results. While some researchers such as Netemeyer, et al. ${ }^{[13,21]}$ have put forward meaningful correlations between work-family conflict and intentions to turnover, other researchers such as Boyar, et al. ${ }^{[25]}$ have revealed negative correlations or no correlation between the two 
variables. Also, Netemeyer and his coworkers ${ }^{[21]}$ in their investigation arguing that work-family conflict would be positively related to intentions to turnover. Important correlations of .14, .25 and .28 between work-family conflict and intentions to turnover have been highlighted by Netemeyer and his peers ${ }^{[21]}$, reflecting from the tests carried out through those three samples. Work-family conflict was conversely related to intent to dwell in an organization and, a high negative correlation of -.43 was put forward from their studies. Boyar, et al. ${ }^{[25]}$ explored the relationship between work-family conflict and intentions to turnover where a negative correlation of -.25 was pointed out between these two variables. Netemeyer, et al. ${ }^{[13]}$ argued that work-family conflict would prognosticate intentions to turnover, and revealed the positive correlation of $.37, .35$, and .45 in their tricultural study. Nonetheless, despite the fact that these results alike to advocate that workers who undergo from high levels of work-family conflict are more plausible have the thirst to leave the organization, when other results imply quite the contrary. With the correlation of .25, the job-spouse dimension of work-family conflict was positively linked to intention to turnover, whereas the job-parent and job-homemaker dimensions of work-family conflict were negatively linked to intention to turnover with correlations of -.25 and -.10 highlighted. Even though there is no explanation for these particular outcomes,

Kossek and Ozeki ${ }^{[19]}$, in a meta-analysis, pointed out no important correlation between work-family conflict and intentions to turnover. Despite the fact that the majority of the results alike to advise a positive relationship between work-family conflict and intentions to turnover, more research needs to be done to investigate the nature of this relationship. The proposed model recommends that intention to turnover is a distal (indirect) consequence of work-family conflict in the view of the fact that its solid relationships to other variables that are also the results of mediated relationships.

Job stress is directly linked to intentions to quit the organization and it is serves as a mediator between work-family conflict and several other variables. In a longitudinal study investigating an integrative model of burnout, a correlation of .3 was found, where job stress is importantly linked to intentions to quit. Sager ${ }^{[26]}$, revealed a meaningful correlation of .45 between job-related stress and intentions to turnover, in a study scrutinizing the link between the two variables, and also pointing out that workers who undergone higher levels of stress have a propensity to face more of the thirst to quit the organization than workers who were undergoing low levels of stress. In a study relating to different cultures, investigating the impacts of stress in teachers, a correlation of .27 has been found and, pointed out that job stress prognosticated intentions to quit an organization. Notwithstanding the fact that there is solid base for the correlations between job stress and intentions to turnover, solid correlations have been pointed out between intentions to turnover and burnout, organizational commitment and job satisfaction, which implies that the correlations between job stress and intentions to turnover may be mediated by these variables. Nevertheless, this model advocates that low job satisfaction, low organizational commitment, and high levels of burnout augur intention to turnover. To summarize, intention to turnover might not be a very close consequence of work-family conflict, but a far-away consequence one that is exhibited when burnout is high, job satisfaction is low and organizational involvement is low. 


\subsubsection{Burnout and Intention to Turnover}

Intention to turnover is one of the principal issues resulting to burnout. Researchers revealed in they study that high levels of burnout prognosticate intention to abandon ones job. Also a longitudinal research conducted by Lee and Ashforth ${ }^{[27]}$, investigating the impacts of stress on intention to turnover, recommended that two (emotional exhaustion and depersonalization) of the facets of burnout would be linked to intentions to abandon, and the results of their research highlighted a meaningful correlations ranging from .18 to .38. These findings correlations insinuating that people who undergone high effects of burnout were more plausible to plan intentions to abandon an organization than those who faced low levels of burnout. Also, in a meta-analysis which generated corrected weighted mean of .16 for personal accomplishments, .31 for depersonalization, and .44 for emotional exhaustion, was found and pointed out that each of the three facets of burnout are correlated with intention to turnover ${ }^{[27]}$. In the same vein of the previous research results obtained, consequently, the model suggested enunciates that burnout will mediate the relationship between job related stress and intentions to turnover.

Hypothesis 8a Burnout will be positively related to intention to turnover

Hypothesis 8b Burnout will mediate the relationship between job stress and intentions to turnover.

\subsubsection{Organizational Commitment and Intention to Turnover}

Research results pointed out that lowered organizational involvement has also been revealed to be a precursor to intention to turnover. Low, et al. ${ }^{[28]}$, found regular and solid backing for the link between organizational commitment and intentions to turnover. Investigating the consequences of job stress and intentions to abandon, Sager ${ }^{[26]}$ discovered a correlation of -.71 reported a solid negative link between organizational commitment and intentions to turnover amidst managers. By testing the samples of entrylevel and upper-level managers, researchers pointed out that organizational commitment importantly prognosticated intention to turnover for both groups of managers. Babakus, et al. ${ }^{[29]}$, in a research investigating the antecedents and outcomes of burnout, also revealed that organizational commitment was conversely linked to intention to turnover for people who had low levels of organizational commitment, were more likely to manifest their desire to leave the organization, than those people who had high levels of organizational commitment. Also, they study results displayed an important correlation of -.41 between organizational commitment and intentions to turnover. It has been also shorted out in a cross-cultural study conducted by Low, et al. ${ }^{[28]}$, by testing sales workers in Australia, that the organizational commitment prognosticated intentions to turnover. The investigators revealed a meaningful correlation of .42 between organizational commitment and intention to turnover. As also testified the results of a meta-analytic which sustained this relationship. Organizational commitment said to contribute directly to intention to turnover and reported a mean weighted correlation of -.54 as discovered Tett and Meyer ${ }^{[30]}$. In a meta-analysis, which resulted with mean weighted correlations ranging from -.18 to -.56 for the relationship between organizational commitment and withdrawal behaviors pointed out that organizational commitment foretells recess behaviors encompassing intentions to turnover. Organizational commitment will then act as a mediator in the job-stress intention to turnover relationship as 
recommends the proposed model.

Hypothesis 9a Organizational commitment will be negatively related to intention to turnover.

Hypothesis 9b Organizational commitment will mediate the relationship between job stress and intention to turnover.

\subsubsection{Job Satisfaction and Intention to Turnover}

Low job satisfaction has also found to prognosticate intention to turnover like it was with organizational commitment. Fortunately, empirical support has been discovered to assert these results. Sager ${ }^{[26]}$ pointed out a meaningful negative correlation of -.69 between job satisfaction and intentions to abandon, in a study his conducted to investigate the effects of job related stress on intention to leave. This result study of Sager urge that people who were less pleased with their jobs had stronger intentions to quit the organization than those who are happier with their duties. Scrutinizing the consequences of work-family conflict, role stress, and emotional exhaustion, in another research, Boles, Johnston and Hair ${ }^{[31]}$ revealed that job satisfaction was related to a worker's intention to turnover; and they yielded in their study, an important correlation of -.60 between job satisfaction and intention to resign from the organization. Also, Babakus and his workmates ${ }^{[29]}$ have sustained that job satisfaction was related to intention to turnover with a meaningful correlation of -.45 highlighted. As for Low, et al. ${ }^{[28]}$, they conducted a cross-cultural study whose result has produced a correlation of -.40 and they deduced that job satisfaction was meaningfully linked to intention to turnover. An important mean weighted correlation of -.58 for the link between job satisfaction and intention to quit have been pointed out by Tett and Meyer ${ }^{[30]}$. In the view of the fact that these results are solid, the proposed model recommends that job satisfaction will mediate the relationship between job stress and to intentions to turnover.

Hypothesis 10a Job satisfaction will be negatively related to intention to turnover.

Hypothesis $\mathbf{1 0 b}$ Job stress will mediate the relationship between job stress and intention to turnover.

\subsection{Empirical Analysis}

In total, four Ivorian industrial companies actually participated in the study. A total of 311 people participated in the survey, of whom 249 were identified as the best for the study. To find possible important differences between the group of employees whose data were included and those whose data have been kept out for all variables in this study, $T$-tests for independent samples were conducted. Thus, between the two groups on any of the nine variables scrutinized in this study. No meaningful differences have been pointed out after the $T$-tests. Finally, a total of 150 participants data have been used to drive the present empirical study.

The proposed theoretical model to be evaluated, SPSS 19.0 has been used to reckon all parameter estimates based on the correlations and standard deviations begot by all study variables. To achieve this, a model has been built in which each latent variable was depicted by a unique indicator, and all parameter assesses were corrected for measurement error utilizing the acquired trustworthiness estimates and observed variances for all elements (variables). Precisely more, following recommendations of researchers such as Bollen ${ }^{[32]}$ and Hayduk ${ }^{[33]}$, the path 
from each latent variable to its sole indicator was set at a value equal to the square root of the reliability, whilst the error variance estimates were set to equal one minus the reliability estimate of each variable.

\subsubsection{Summary of Standardized Coefficients}

The standardized coefficients pointed out for the proposed model will now be summarized and presented. As shown in Table 4, mostly part of the correlations coefficients determined showed themselves meaningful. Moreover, these correlations are in the direction of the original hypotheses.

Concerning the effect of job stress on work-family conflict, a high standardized path coefficient of .64 has been outlined. About Hypothesis 1 which specified that work-family conflict would predict job stress, backing has been afforded.

A support has been also established for Hypothesis 2. This hypothesis bolstered that work-family conflict would predict life stress. For this support of Hypothesis 2, a small direct standardized coefficient of .20 has been revealed.

In view of that the hypotheses that foretold direct effects of work-family conflict on jobstress and life stress were both corroborated, backing pointed out for hypotheses foretelling indirect relationships will now be introduced. Producing a standardized path coefficient of .69, the effect of job stress on burnout was high and in the direction hypothesized in the first place.

From the moment that work-family conflict meaningfully foretells job stress, and the jobstress/burnout causal relationship was justified, Hypothesis 3 which asserts that job stress mediates the relationship between work-family conflict and burnout was propped.

Table 4 Means, standard deviations, and correlations for study variables

\begin{tabular}{|c|c|c|c|c|c|c|c|c|c|c|c|}
\hline Variables & Mean & SD & 1 & 2 & 3 & 4 & 5 & 6 & 7 & 8 & 9 \\
\hline $\begin{array}{l}\text { 1. Work-family } \\
\text { Conflict }\end{array}$ & 3.39 & .85 & & & & & & & & & \\
\hline 2. Job Stress & 28.63 & 9.58 & $.60^{* *}$ & & & & & & & & \\
\hline 3. Life Stress & 2.75 & .66 & $.38^{* *}$ & $.41^{* *}$ & & & & & & & \\
\hline 4. Burnout & 2.17 & .74 & $.47^{* *}$ & $.69^{* *}$ & $.50^{* *}$ & & & & & & \\
\hline $\begin{array}{l}\text { 5. Organizational } \\
\text { Commitment }\end{array}$ & 4.96 & .98 & $-.25^{* *}$ & $-.43^{* *}$ & $-.66^{* *}$ & $-.61^{* *}$ & & & & & \\
\hline 6. Job Satisfaction & 39.41 & 11.54 & $-.28^{* *}$ & $-.49^{* *}$ & $-.25^{* *}$ & $-.54^{* *}$ & $.49^{* *}$ & & & & \\
\hline 7. Job Performance & -.03 & .96 & -.04 & .00 & -.09 & -.10 & $.26^{*}$ & .15 & & & \\
\hline 8. Life Satisfaction & 37.26 & 10.61 & $-.28^{* *}$ & $.16^{* *}$ & $-.55^{* *}$ & $-.47^{* *}$ & $.37^{* *}$ & $.42^{* *}$ & $.19^{* *}$ & & \\
\hline 9. Intention to Quit & 2.87 & 1.17 & $.22^{* *}$ & $.37^{* *}$ & $.23^{* *}$ & $.42^{* *}$ & $-.65^{* *}$ & $-.05^{* *}$ & -.16 & $-.38^{* *}$ & \\
\hline $\begin{array}{l}\text { 10. Prototypical } \\
\text { Implicit } \\
\text { Leadership }\end{array}$ & 4.52 & .45 & .08 & .00 & .01 & -.08 & .11 & .11 & .04 & $.23^{* *} .03$ & \\
\hline
\end{tabular}

Despite the fact that the job stress/job performance relationship was implied in the model tested, the outcomes pointed out for this path was not important. By dint of this scarcity of 
importance, no backing was afforded for Hypothesis $6 \mathrm{~b}$ which purported that job-stress will mediate the relationship between work-family conflict and job performance. Nonetheless, a meaningful path coefficient of -.59 was pointed out for the relation between life stress and life satisfaction.

In view of the already important path pointed out between work-family conflict and lifestress, Hypothesis 7b which sets out that life stress would mediate the relation between work family conflict and life satisfaction was propped. Exclusively, partial backing was revealed for Hypotheses 9b. Thus, Hypothesis 9b foretold that the relation between work-stress and intention to quit would be mediated by organizational commitment.

The proposed model, nevertheless tested the meditative role performed by organizational commitment in the burnout/intention to quit relationship. Between organizational commitment and intentions to quit, an important standardized path coefficient of -.65 has been pointed out. Nonetheless, in view of that job stress was not any more longer tested as being in a direct relationship on organizational commitment, Hypothesis $9 \mathrm{~b}$ was only partially propped. There is no prop pointed out for Hypothesis 10b which foretold that job satisfaction would mediate the job stress/intention to quit relationship. For the predictive effect of job satisfaction on intention to quit, a non-important path coefficient of -.05 has been pointed out.

Independently of the outcomes corroborating paths hypothesized in the first place, results of the investigative paths scrutinized in the model also afforded coefficients that were for the most part in the direction purported by the model. The standardized coefficient of .41 pointed out for the effect of job stress on life stress, was in the direction looked for. With a standardized coefficient of .16, job stress had with astonishment a small effect positive on life satisfaction. In short, this outcome was not in the direction that has been looked for. Burnout generated high standardized coefficients for its impact on organizational commitment and job satisfaction, and that were both in the direction recommended. A coefficient of -.45 has been found for the direct effect of burnout on organizational commitment, whereas a coefficient of -.66 was produced for the direct effect of burnout on job satisfaction. Job satisfaction shown a high standardized coefficient of .42 for its effects on life satisfaction. Once, and for all, job satisfaction had effects in the direction looked for on organizational commitment with standardized coefficient of .49 and job performance with standardized coefficients of .26.

To summarize, our proposed model engendered several relationships that were coherent with many of the hypotheses defined. In spite of that, it is important to perceive that all of these analyses need to be deeply discussed need to be weighed in the light of previous studies by previous researchers and the various indices to check the goodness of fit of data.

\subsubsection{Discussion of the Correlational Results}

Previous outcomes of studies conducted by researchers such as Boles, et al. ${ }^{[31]}$ and asserted the meaningful correlation between work-family conflict and job-stress, and they also pointed out that there were the important positive relationships between work-family conflict and jobstress. An important positive relationship between work-family conflict and life stress was highlighted by researchers such as Frone, et al. ${ }^{[12]}$ and Parasuraman, et al. ${ }^{[14]}$. Between jobstress and burnout, the meaningful positive correlation pointed out afforded support, among 
others researchers Netemeyer, et al. ${ }^{[21]}$, Kock ${ }^{[16]}$. The study results were corroborated the meaningful negative relationship pointed out between job-stress and organizational commitment in this study. Between job- stress and job satisfaction, the meaningful negative relation pointed out and, was confirmed by the negative relationship between the two variables highlighted in our study. In spite of that, the findings outlined by Viator ${ }^{[34]}$ in the light of the relationship between work stress and job performance were not propped. Nevertheless, these findings propped the outcomes which put in light no important relationship between job stress and job performance. Between life stress and life satisfaction, the meaningful negative relation found, propped the outcomes demonstrated by $\mathrm{Lu}^{[23]}$ and, Chang \& Sanna ${ }^{[24]}$. As regards to variables of the correlations that were put forward to be linked to intention to quit as hypothesis in the current study, also propped previous research. Lee and Ashforth ${ }^{[27]}$ study outcomes pointing out that burnout was positively linked to intention to quit were coherent with the findings highlighted in the current study. The negative and important relationship pointed out between organizational commitment and intention to quit propped previous outcomes recommended by Sager ${ }^{[26]}$. The outcomes of the actual study finally propped findings pointed out by Tett \& Meyer ${ }^{[30]}$, and by highlighting a meaningful negative correlation between job satisfaction and intention to quit.

As a consequence, the correlational outcomes pointed out in the current study, for the most part, add to the generally high level of prop for most of these relationships revealed in the literature. These correlations also come up with some backing for the negative spillover model. The relationship between work-family conflict and job stress and life stress has shown an evidence prop for the spillover impact. High levels of work-family conflict was positively correlated to both job stress and life stress which implies that amplification of inter-role conflict was correlated to intensification of presentiments of pressure from each domain there thereby propping the negative spillover hypothesis. The meaningful positive relations between job stress and burnout, and burnout and intentions to quit pointed out in the current study has also revealed an evidence negative spillover. Notwithstanding the fact that the outcomes demonstrated here do prop the spillover model more causal outcomes require to be scrutinized so as to further corroborate obviousness of the spillover effect.

Despite everything, this proposed model should be scrutinized, and the lack of a meaningful relationship pointed out between job stress and job performance must be fastened. In addition, the fact that problems with the job performance ratings led to no important outcomes, this insignificant data should not be allowed to cast a shadow over the solid prop, and spillover suggestions made remarkable by the other correlational outcomes.

\subsubsection{Robustness Analysis}

Six indices of overall model fit: Chi square $\left(\chi^{2}\right)$, goodness for fit index (GFI), adjusted goodness of fit index (AGFI), comparative fit index (CFI), root mean square error of approximation (RMSEA) and standard root mean square (SRMR) were inspected to assess the fit of the proposed model. The presence of a nonmeaningful Chi-square, GFI, AGFI, and CFI values above .90 , and SRMR values below .08 are as a rule, said to be symptomatic of allowable model fit, with conformity to these indices.

In Table 5, the Goodness of fit indices for the proposed model that will be discussed in the 
coming step are summarized.

Table 5 Goodness of fit summary

\begin{tabular}{ccccccccc}
\hline Indices & df & $\chi^{2}$ & $P$ & RMSEA & SRMR & GFI & AGFI & CFI \\
\hline Values & 22 & 40.02 & $<.01$ & .08 & .06 & .94 & .88 & .97 \\
\hline
\end{tabular}

Note: $N=187$; RMSEA $=$ root mean square error of approximation; SRMR = standard root mean square; GFI = goodness for fit index; AGFI = adjusted goodness of fit index; CFI = comparative fit index.

The data reported in Table 5 point out a slightly high and non-meaningful Chi-square value for the proposed model and highlights a good fit to the data, $\chi^{2}(22, N=187)=40.02, p<.01$.

Also, the investigation of other fit indices in like manner, underlined a good model fit. Almost all goodness of fit indices outdone the minimum point of reference recommended by Bollen $^{[32]}$. When RMSEA $=.08$, is just at the maximum point of reference predetermined by McDonald and $\mathrm{Ho}^{[35]}$. Standardized $\mathrm{RMR}=.06$ is considerably lower than the .08 point of reference recommended. The goodness of fit indices also pointed out that GFI is above the minimum .90 point of reference recommended by Bentler ${ }^{[36]}$, GFI $=.95$, however AGFI is below the minimum point of reference (.88). As well as GFI $=.94$, CFI $=.97$ are above their minimum point of reference.

Despite the fact that only one index (AGFI) does not meet the required level, the analyzed indices somehow depict that the data collected in this present study fit the proposed model.

\section{Conclusion and Contribution}

Work-family conflicts generally refer to the way in which individuals combine work and family responsibilities. Several researchers have drawn from the work of Greenhaus and Beutell ${ }^{[2]}$ that the relationship between family and work is compromised in the event of conflict between different roles, such as worker and parent. Conflict occurs when the demands of an individual's employment interfere with their ability to meet their family responsibilities and vice versa. The more tasks and responsibilities accumulate, the greater the risk of conflict; individuals having a limited amount of time, energy and focus to devote to each role.

Testing an inclusive model of work family conflict was the ambition of the present research. First of all, through a pilot study we fixed the theoretical context of our model. The validation of the concept of spillover theory in the Ivorian context allow to draw an exhaustive model to identify immediate proximal reactions, which would in turn prognosticate distal egresses by means of mediated correlations.

The results point out that most part of the correlations coefficients determined showed themselves meaningful. These correlations are in the direction of the original hypotheses. Firstly, it has been revealed an important correlation between work-family conflict and work stress in the speculated direction of this research work. Also, a positive and important correlation between work-family conflict and life stress is highlighted. The link between work stress and burnout highlights a positive and meaningfully correlation coefficient. Secondly, the correlation coefficient between work stress and organizational commitment showed an important and negative relationship, as well as the correlation between work stress and job satisfaction. Robust 
negative coefficient of correlations was found respectively between burnout and organizational commitment, job satisfaction and intention to quit as well as life stress and life satisfaction. Finally, no relationship was put forward between work stress and job performance.

Despite of the fact that problems with the job performance ratings led to no important outcomes, this insignificant data should not be allowed to cast a shadow over the solid prop, and spillover suggestions made remarkable by the other correlational outcomes. Overall, the correlations results demonstrate that work-related, non-work-related, and stress-related have a great impact on conflict between work and family.

In addition to the significant correlations coefficients (in the expected ways), it is important to notify that the proposed model is adapted to Ivorian context. The investigation of fit indices: Chi square, GFI, CFI, RMSEA and SRMR in like manner, underlined a good model fit. Almost all goodness of fit indices outdone the minimum point of reference recommended by Bollen ${ }^{[32]}$ and McDonald \& $\mathrm{Ho}^{[35]}$, and only one index, AGFI does not meet the required level. The analyzed indices somehow depict that the data collected in this present study fit the proposed model.

Thus, the results of the model study were also hopeful and seem to indicate that a lot of work has been done in order to capture an adequate model that explains the impact of work-related, non-workrelated and stress-related factors on work-family conflicts. Since the main contribution of this study was a solid perceptible framework as supposed, this real study highlighted and drew attention to several dilemmas which must be dealt with in research on conflicts between work and family in particular distal and proximal relationships before we really gain a comprehensive understanding of the concept and its impacts in Cote d'Ivoire. It is perhaps predicted that this study will be one of the first in this research to understand workfamily conflict issues in terms of work, non-work and stress outcomes.

The findings of the current study enhance the complexities embroiled in the research of work-family conflict field. These outcomes demonstrate that the consequences of work-family conflict come by in a complex network of direct and indirect relationships. In order to fully understand these relationships, researchers must continue to test models until the most generalizable model is found. In view of the expansion in diversity pointed out in the work force today, the requirement for a generalizable model of work-family conflict is apparent.

The outcomes of the current study also reveal that the role of time has been passed over and/or underappreciated in work-family conflict research field. To really grasp the consequences of work-family conflict, not only do we have to evaluate and test theoretical relationships between variables, we also need to pay close attention to the effects of time on the consequences of work-family conflict. The outcomes of the current study appear to imply that over time, the consequences of work-family conflict spurt out in a series of progressively complex relationships. Hence, to fix these consequences and/or to impede these consequences, it is meaningful to comprehend the role performed by time in the development of each complexity in order to get the better design strategies.

The outcomes of the current study also reveal that the role of time has been passed over and/or underappreciated in work-family conflict research field. To really grasp the impacts, not only do we have to evaluate and test theoretical relationships between variables, we also 
need to pay close attention to the effects of time on the impact. The outcomes of the current study appear to imply that over time, the impacts on work-family conflict spurt out in a series of progressively complex relationships. Hence, to fix these impacts and/or to impede these consequences, it is meaningful to comprehend the role performed by time in the development of each complexity in order to get the better design strategies.

The present study's outcomes also recommend one impactful implication in terms of using of results. In the view of that work-family conflict emerge in a complex framework that drives work, non-work and stress related outcomes, endeavors to get rid of or hamper these consequences will have to spurt from the mix efforts of all parties implicated. Hence, in order to staunch effectively with work-family conflict, the worker, the worker's family and the employer are all require to take resolutions to forestall work-family conflict and its consequences in order for the best solution to be set up. Employers could endeavor to set the work environment up in such a way as to minimize work-related consequences, while the worker and his or her family could take steps to staunch the non-work and stress-related outcomes.

In the end, these findings recommend that, in the light of the complex framework of direct and indirect relationships that make up the proposed model of work family conflict, attempts to monitor or master the impacts should be made at a point early in the model (e.g., trying to eliminate job stress so as to impede the negative outcomes of burnout and intention to quit that appear if the earlier impact is not monitored). Advance interposition could be the key to hamper these influences. In lieu of permitting the impact to grow up to the stage that they become crushing early intervention may accommodate undergoes of work-family conflict to perform more effectively.

\section{References}

[1] Cantin E. La conciliation des responsabilities familiales et professionnelles, Le March du travail, 1994: 67-69.

[2] Greenhaus J, Beutell N. Sources of conflict between work and family roles. Academy of Management Review, 1985, 10(1): 76-88.

[3] Carlson D S, Kacmar M K. Work-family conflict in the organization: Do life role values make a difference? Journal of Management, 2000, 26: 1031-1054.

[4] Nielson T R, Carlson D S, Lankau M J. The supportive mentor as a means of reducing work-family conflict. Journal of Vocational Behavior, 2001, 59: 364-381.

[5] Tremblay D G. Conciliation emploi-famille et temps sociaux. Qubec-Toulouse, Presses de l'universit du Qubec et Octares, 2004.

[6] St-Onge S, Renaud S, Guerin G, et al. Verification dun modele structurel a legard du conflit travail-famille. Relations industrielles/Industrial relations, 2002, 57(3): 491-516.

[7] Xu L. View on work-family linkage and work-family conflict model. International Journal of Business and Management, 2009, 12(4): 229-233.

[8] Friedland J, Cole B C. From Homo-economicus to Homo-virtus: A system-theoretic model for raising moral self-awareness. Journal of Business Ethics, 2017: 128-134.

[9] Ejohwomu O A, Olalekan S O, Ka C L. Nigerias construction industry: Barriers to effective communication. Engineering, Construction and Architectural Management, 2017, 24(4): 652-667.

[10] Bergkvist L, Taylor C R. Leveraged marketing communications: A framework for explaining the effects of secondary brand associations. AMS Review, 2016, 6(3-4): 157-175.

[11] Sucan D S, Marhan A M, Micle M I. Intention to quit job consequence of work-family conflict. A Romanian pilot study. Revista de Psihologie, 2013, 60(3): 253-259. 
[12] Frone M R, Yardley J K, Markel K S. Developing, testing, and integrative model of the work-family interface. Journal of Vocational Behavior, 1997, 50: 145-167.

[13] Netemeyer R G, Brashear-Alejandro T, Boles J S. A cross-national model of jobrelated outcomes of workrole and family role variables: A retail sales context. Journal of the Academy of Marketing Science, 2004, 32: 49-60.

[14] Parasuraman S, Purohit Y S, Godshalk V M, et al. Work and family variables, entrepreneurial career success, and psychological well-being. Journal of Vocational Behavior, 1996, 48: 275-301.

[15] Maslach C, Schaufeli W B, Leiter M P. Job burnout. Annual Review of Psychology, 2001, 52: 397-422.

[16] Hock R R. Professional burnout among public school teachers. Public Personnel Management, 1988, 17: $167-187$.

[17] Mowday R T, Steers R M, Porter L W. The measurement of organizational commitment. Journal of Vocational Behavior, 1979, 14: 224-247.

[18] Jamal M. Relationship of job stress to job performance: A study of manager and blue collar workers. Human Relations, 1985, 38: 409-424.

[19] Kossek E E, Ozeki C. Workfamily conflict, policies, and the joblife satisfaction relationship. A review and directions for organizational behaviorhuman resources research. Journal of Applied Psychology, 1998, 83: 139-149.

[20] Boles J S, Howard W G, Donofrio H H. An investigation into the inter relationships of work-family conflict, family-work conflict and work-satisfaction. Journal of Managerial Issues, 2001, 13: 376-387.

[21] Netemeyer R G, Boles J S, McMurrian R. Development and validation of work-family conflict and workfamily conflict scales. Journal of Applied Psychology, 1996, 81: 400-410.

[22] Hart P. Predicting employee life satisfaction: A coherent model of personality, work and non-work experiences, and domain satisfactions. Journal of Applied Psychology, 1999, 84: 564-584.

[23] $\mathrm{Lu} \mathrm{L}$. The relationship between subjective well-being and psychosocial variables in Taiwan, China. The Journal of Social Psychology, 1995, 135: 351-359.

[24] Chang E C, Sanna L J. Optimism, accumulated life stress, and psychological and physical adjustment: Is it always adaptive to expect the best? Journal of Social and Clinical Psychology, 2003, 22: 97-115.

[25] Boyar S L, Maertz C P, Pearson A W, et al. Work-family conflict: A model of linkages between work and family domain variables and turnover intentions. Journal of Managerial Issues, 2003, 15: 175192.

[26] Sager J K. A structural model depicting Salespeople's job stress. Journal of the Academy of Marketing Science, 1994, 22(Winter): 74-78.

[27] Lee R T, Ashforth B E. A further examination of managerial burnout: Toward an integrated model. Journal of Organizational Behavior, 1983, 14: 3-20.

[28] Low G S, Cravens D W, Grant K, et al. Antecedents and consequences of sales person burnout. European Journal of Marketing, 2001, 35: 587-611.

[29] Babakus E, Cravens D W, Johnston M, et al. The role of emotional exhaustion in sales force attitude and behavior relationships. Academy of Marketing Science, 1999, 27: 58-70.

[30] Tett R P, Meyer J P. Job satisfaction, organizational commitment, turnover intention, and turnover: Path analyses based on meta-analytic findings. Personnel Psychology, 1993, 46: 259-293.

[31] Boles J S, Johnston M W, Hair Jr J F. Role stress, work-family conflict and emotional exhaustion: Interrelationships and the effects on some work-related consequences. Journal of Personal Selling and Sales Management, 1997, 17: 17-29.

[32] Bollen K A. A new incremental fit index for general structural equation models. Sociological Methods in Research, 1989, 17: 303-316.

[33] Hayduck L A. Structural equation modeling with LISREL. University Press, Johns Hopkins, Baltimore, 1987.

[34] Viator R E. The association of formal and informal public accounting mentoring with role stress and related job outcomes. Accounting Organizations and Society, 2001, 26: 73-93.

[35] McDonald R P, Ho M H R. Principles and practice in reporting structural equation analyses. Psychological Methods, 1999, 7: 64-82.

[36] Bentler P M. Comparative fit indices in structural models. Psychological Bulletin, 1990, 107: 238-246. 